\title{
COMÉRCIO ELETRÔNICO: UMA VISÃO DO DIREITO BRASILEIRO
}

\author{
Luiz Olavo Baptista \\ Professor Titular do Departamento de Direito Internacional \\ da Faculdade de Direito da Universidade de São Paulo
}

\begin{abstract}
Resumo:
O presente artigo examina o comércio eletrônico e seus reflexos jurídicos, sob a óptica do Direito brasileiro. Inicialmente, explica a abrangência da expressão, através de analogias com atividades comerciais tradicionais, apontando como predecessores dessa nova forma de se fazer comércio as atividades dos mascates e as vendas por catálogos. Examinam-se de forma mais detalhada as operações de compra e venda na rede e fora dela e os pagamentos efetuados através de documentos eletrônicos. Abordam-se os critérios distintivos das operações eletrônicas, quais sejam, a presença do elemento eletrônico, a ausência de suporte físico e as questões envolvendo a segurança do negócio. Por fim, verifica-se, sucintamente, o problema da divisão de responsabilidade dos vários personagens envolvidos na cadeia formada entre produtor e comprador final, e a questão da internacionalidade das operações.
\end{abstract}

\section{Abstract:}

This paper examines the electronic commerce and its legal effects, under the approach of the Brazilian law. It begins by explaining the comprehension of the expression, making analogies with traditional commercial activities, appointing as predecessors of this new form of making commerce the activities performed by the "mascates" and "sales by catalog". It examines in a more detailed way the sales transactions - inside and outside the net and the payments made through electronic documents. The distinctive criteria of the e-commerce transactions are assessed, i.e., the presence of the electronic element, the absence of physical support and the aspects related to the safety. Finally, it refers to the problem of the division of responsibility between the various personages involved in the chain formed by the manufacturer up to the final consumer, and the international aspects of the transactions.

Unitermos: comércio eletrônico; compra e venda; pagamentos; documentos eletrônicos. 
Introdução.

A presença da informática marca este fim de século. Os computadores e os "chips" estão presentes nos nossos relógios, nos fogões que aquecem a nossa comida, na regulagem dos freios de nossos automóveis, nos computadores e telefones que estão sobre as nossas mesas, entre muitos outros objetos.

A presença da informática não se reduz à existência dos aparelhos, ela se estende também, sem sombra de dúvida, a outros domínios: o da transmissão de notícias e o das trocas de dados e informações. Serve também para o estabelecimento de novos canais de comunicação entre as pessoas, ensejando, assim, a criação de uma nova maneira de fazer o comércio.

Mas, ao mesmo tempo que a informática propõe novos instrumentos, as pessoas continuam a recorrer aos procedimentos tradicionais. Assim, se se pode falar em uma nova maneira em fazer o comércio, quando nos referimos ao chamado comércio eletrônico e aos EDI (Electronic Data Interchange), também temos de recordar que a informática simplesmente permite fazer, mais depressa e eficientemente, aquilo que antes se alcançava por outras maneiras.

Com o comércio eletrônico ela traz a vitrine do comerciante até o consumidor, sem que este precise sair de sua casa ou do seu escritório para vê-la. Ao mesmo tempo o comerciante não precisa mais de um estabelecimento real, passando a usar um estabelecimento virtual.

Também nas operações financeiras, por exemplo nos pagamentos, as operações bancárias tradicionais como as transferências de dinheiro entre contas, os pagamentos, as cobranças e descontos de duplicatas e faturas - passam a ser eletrônicas, circulando pelo meio digital, e realizando, mais depressa e melhor, tarefas que as pessoas faziam por si. ${ }^{\prime}$ A moeda escritural é, agora, digital e eletrônica.

Vamos, ainda, ver a informática usada pelos operadores da Bolsa, nas compras e vendas de títulos de crédito, inclusive automatizando as decisões, escolhendo o momento em que as vendas ou compras ocorrerão, a partir de parâmetros predeterminados.

Estas novas tecnologias, como qualquer outra atividade ou criação humana, devem se submeter ao Direito, e ser objeto de regulamentação e estudo.

1. Baptista, Luiz Olavo. Transferências Eletrônicas Internacionais de Fundos, ed. Acadêmica. USP-SP, Tese de Livre-docência. 
Se elas são sujeitas às normas existentes e, por isto, afetadas pelo Direito, também o afeta de alguma forma. Exigem-lhe, pelo menos, outras maneiras de interpretar as regras e aplicá-las às situações que criam e que são novas.

As novas tecnologias são afetadas pelo Direito, porque é este que fornece o quadro para as condutas humanas que se desenvolvem. Afetam o Direito, porque este reage a situações que não haviam sido até então cogitadas e que decorrem do uso dos meios eletrônicos.

Uma reflexão sobre as atividades desenvolvidas no campo da informática e seus reflexos jurídicos, certamente, seria muito extensa. Por isso, vamos nos cingir, aqui, a apenas uma questão, a do comércio eletrônico, e sob a óptica do Direito brasileiro.

Vejamos, primeiro, o que compreende esta expressão e, delimitado o seu domínio, encaremos a sua regulamentação positiva.

\section{Domínio das operações de comércio eletrônico}

O comércio eletrônico é, de certa forma, o retorno do "mascate"

Todos nós temos a lembrança deste personagem, freqüente nos tempos coloniais, ainda existente no início do século $\mathrm{XX}$, e que visitava a casa das pessoas na zona rural ou nos bairros afastados, levando mercadorias de pequeno porte, e imagens ou amostras de outras que entregaria quando encomendadas pelo comprador interessado.

O mascate não-tinha estabelecimento próprio. Ia até o comprador, e oferecia-lhe bens que, em grande parte, não-tinha em estoque e adquiriria para entregar, quando encomendados.

A especificidade da atividade comercial do mascate era a de se colocar diante do consumidor final e oferecer-lhe, verbalmente, a mercadoria, eliminando a necessidade de deslocamentos físicos deste, propondo-lhe uma variedade de bens. Do ponto de vista do Direito, entre outras características, ele era um comerciante independente, sem estabelecimento fixo, cujos contratos eram, via de regra, orais.

O comércio eletrônico retoma esta tradição, com novos meios.

O programa de acesso (browser) - como fazia o burro usado pelo mascate leva o site do comerciante, que corresponde à mala do seu ancestral, até a casa do comprador, trafegando pelos caminhos da rede. 
O comprador potencial examina as mercadorias e catálogos, e se alguma coisa lhe convier, tal como faziam seus avós com o mascate, encomenda-a, pagando contra a entrega. $O$ contrato passado entre as partes não repousa no suporte a que nos habituamos, o papel, mas, sim, no ambiente eletrônico, circulando por meio tão-incorpóreo quanto o ar, em que os contratos orais trafegam e, permanece, residindo em memórias digitais, tão-falíveis quanto a humana.

Não é difícil prosseguir nas analogias, lembrando a semelhança entre os "electronic malls" e as antigas feiras medievais, do tipo que ainda se vê no sertão ou no Nordeste brasileiro.

Comerciantes sem estabelecimento, como os mascates, produtores locais, e provedores de diversão, reúnem-se num local predeterminado, expondo, na mídia eletrônica, lado a lado, suas mercadorias e serviços, para maior facilidade do comprador.

Antes da rede havia a presença física dos comerciantes e do comprador face a face e as mercadorias (ao menos algumas delas) poderiam também estar ali, fisicamente; isso não é mais necessário.

Poderíamos ainda apontar, entre os predecessores do comércio eletrônico, as vendas por catálogo. O comerciante vendia por correspondência, rementendo aos compradores, em perspectiva, um catálogo, onde estes escolhiam as mercadorias, manifestando a aceitação da oferta por carta ou telefone. O pagamento se fazia pelo reembolso postal, por ordem de pagamento, ou cheque, antecipado ou contra a entrega.

Talvez o exemplo mais conhecido hoje de comércio eletrônico seja a Amazon. O fato de que essa livraria tem sua publicidade em quase todos os "sites" da Internet torna-a facilmente reconhecível, e lhe dá uma presença ativa. O comprador não-precisa ir até ela. Ela figurativamente "bate à porta" dos "internautas"

Examinando sua forma de agir vemos que é como a de um mascate de livros, um desses vendedores a domić́lio que ainda vão aos escritórios de advocacia e ao fórum, oferecendo as novidades que trazem na mala, com os catálogos das grandes livrarias. O "ícone" ou a publicidade da Amazon aparece nas bordas de inúmeros sites da rede, onde um simples "clic" do mouse faz com que apareça o seu "domínio" Lá o cliente examina os livros em oferta, ou procura o que lhe convém há mecanismos para isto e escolhe o que comprar.

Várias metáforas são usadas, como a do "carrinho de compras" que facilitam os atos dos compradores. O cliente compra, paga com cheque ou cartão 
e, pouco depois, recebe o livro, que, quando não está no estoque do vendedor, é comprado por este para a entrega ao interessado. Ou paga a mercadoria contra a entrega.

Pode-se, então, para efeitos jurídicos, comparar esta operação com uma compra por catálogo. Mas se diferencia desta pela interação e diálogo que se pode estabelecer, via Internet, seja com um computador que contém a base de dados, seja com outra pessoa, o que torna mais ilustrativa a metáfora do mascate, ou a assimilaria à compra por telefone. Logo, achamo-nos diante da figura do contrato â distância.

Uma conseqüência destas formas de agir é que em geral a mercadoria será entregue depois e não-retirada no ato. Isto nos traz, também, conseqüências jurídicas conhecidas.

$\mathrm{Na}$ livraria eletrônica como na compra por catálogo, ainda é preciso aguardar que o livro seja entregue, por um portador ou pelo Correio (isso, porém, até que o livro passe, também, a ser eletrônico, quando a entrega será imediata, como acontece com os programas de computador, músicas, etc). Quem sabe se não é por causa de um hábito de compras por catálogo que a Amazon, como outros "estabelecimentos eletrônicos" aparece nos EUA em primeiro lugar?

Não-ocorre aquilo de que os intelectuais tanto apreciam, que é o contato com o livro, objeto físico, e até o prazer de começar a lê-lo antes mesmo da compra ter-se concretizado. Isso se coaduna com o hábito norte-americano da compra de livros técnicos (e outros) diretamente do editor, por catálogo.

Como veremos, no comércio eletrônico não existem só o comerciante e o cliente. Há outros personagens.

Tal como as pessoas vão procurar os shopping centers para evitarem de andar muito procurando lojas e produtos, assim, também, a existência do seu equivalente eletrônico se justifica pela facilidade que terão os consumidores em encontrar os produtos que buscam.

Os "mercados eletrônicos" (electronic shopping malls), isto é, os domínios que reúnem um número de comerciantes, vendedores de flores, de lívros, de discos, etc., ${ }^{2}$ tem um responsável. Este é um dos personagens, além do comprador e do vendedor.

2. O fato de que o comprador acha todo o tipo de mercadorias a partir de um mesmo local (eletrônico) é que justifica a existência dos electronic shopping malls. 
Intervém ainda a instituição financeira que cuida do pagamento, assim como o transportador da mercadoria que a entrega, além do produtor do software, do provedor de acesso, dos operadores da rede e outros.

Cada um desses personagens desempenha um papel específico, e o seu relacionamento com os demais é objeto de regulamentos e contratos.

O comércio eletrônico faz-se dentro da rede, convém lembrar. Esta é a nova realidade, a existência de um novo mundo, chamado de virtual. Apesar da novidade, a seqüência clássica da compra e venda - oferta e procura, ajuste quanto ao preço e condições de entrega, e a formação do contrato, continua a existir. Assim também a problemática do preço, da entrega, do transporte, etc.

Os problemas clássicos da compra e venda: a qualidade do objeto, a garantia do pagamento, etc. estão presentes, da mesma forma que nas operações tradicionais.

A rede, que se desenvolveu na Internet ou o World Wide Web, se preferirem, deve ser objeto de nosso olhar, sob vários outros aspectos que tradicionalmente se relacionam com as compras e vendas. Por exemplo, a proteção ao consumidor e sua segurança: ou os direitos do vendedor, tendo em vista as modalidades de pagamento que ali se podem realizar.

Vejamos, então, primeiro, as características das compras e vendas e, depois, as dos pagamentos.

\section{A. Compra e venda}

A compra e venda é a mais comum das operações do comércio. Ela veio, pela sua praticidade, substituir as trocas. Como César, "veio, viu e venceu" No Brasil é regulada pelo Código Comercial, de 1850.

Entretanto, não-permaneceu imune ao tempo. A compra e venda na história vem sofrendo modificações, desde as suas origens. Ritualizada com conotações religiosas do Direito Romano, foi simplificada na evolução do mesmo, Iaicizou-se com o tempo. Perdeu o formalismo, e, agora, através dos meios eletrônicos, parece ter sido mais simplificada. Mas seria verdade isso?

A compra e venda eletrônica, como disse, faz-se dentro da rede. 


\section{A compra e venda na Rede}

O procedimento é o clássico, sob o ângulo jurídico, e tem início pela oferta.

A oferta, se faz tal como nos catálogos impressos em papel, através da apresentação da imagem, das características técnicas da mercadoria (ou serviço), do seu preço, das condições relativas ao pagamento, e à sua entrega.

A colocação da mercadoria na tela do computador, como no papel do catálogo, por essa forma, do ponto de vista do Direito, assume a característica de uma oferta.

O comprador, ao vê-la, procede ao exame das características, e se o bem oferecido responder às suas expectativas, escolhe-o. Ao manifestar a sua intenção de compra, responde à oferta, por uma comunicação, feita, via de regra, por via eletrônica. Em geral, a aceitação está associada ao pagamento, este também pela mesma via.

Assim, as operações de compra e venda na rede caracterizam-se como ofertas e aceitações instantâneas, não permitindo a negociação. É claro que a Internet pode ser usada (como o telefone, ou o Correio) para as partes negociarem, nos moldes tradicionais. Mas isto não é usual, ainda que possível.

\section{Fora da rede}

Há, ainda, operações de comércio eletrônico fora da Internet.

Entre estas estão as feitas nos quiosques eletrônicos, onde há um terminal escravo de computador, em que as pessoas recebem a oferta e aceirando-a fazem a compra das mercadorias ou serviços. São o equivalente dos vendor machines.

É comum vermos, nos aeroportos, um quiosque eletrônico que vende um seguro de vida ou de bagagem para os viajantes, e há, nos EUA, os que vendem bilhetes de aviões.

Outros, situados em lugares de muita circulação, vendem entradas para o teatro, ou bilhetes de trem ou de metrô.

Essas máquinas fazem automaticamente a oferta, recebem e registram a aceitação e permitem que o comprador faça o pagamento, entregando o objeto do negócio, concretizando o contrato de venda e compra e a liquidação da operação. 
O propósito da máquina, associado às imagens e informações exibidas na sua tela, corresponde à expressão de uma oferta da mercadoria ou serviço por parte do vendedor. O comprador, respondendo à oferta, pagará pelo bem adquirido em espécie, através de moedas ou fichas, ou de um meio eletrônico, por exemplo mediante o uso do seu cartão eletrônico de pagamentos.

\section{B. Pagamento}

O pagamento, como se disse, se faz através de várias formas, que incluem o chamado "documento eletrônico" cujo uso é tão-grande como o dos cartões de pagamento.

Pode ocorrer diretamente ou através de um intermediário, em geral uma empresa operadora de cartões de pagamento ou de crédito. Através de uma transferência eletrônica de dados, o comerciante ou o comprador informam à operadora o valor a ser pago, o número do cartão do comprador, e o da conta do favorecido. A empresa operadora do cartão faz com que um banco efetue a transferência, cujo valor se encarrega de recuperar oportunamente. O papel nãoexiste, e as transferências são feitas sem a presença ou interferência humana, as pessoas agindo somente para dar partida ao processo.

\section{Os cartões de pagamento}

Quando se utilizam os smart cards, ou cartões com memória, o comprador simplesmente digita o seu código no terminal portátil, à guisa de sua assinatura, e o pagamento é perfeccionado.

Quando o terminal (portátil ou-não) fornece uma pequena tira de papel, que reproduz os dados da operação, está apenas atendendo à sua segurança psicológica e entregando ao usuário um lembrete daquilo que foi feito.

A operação já está realizada, os pagamentos já estão feitos, e os efeitos jurídicos alcançados, sem que se tenha necessidade de papel, que não-vale como prova. O papel aí é apenas uma lembrança do passado, com efeitos tranquiilizadores para o usuário.

Ainda subsistem os cartões com tarja magnética, cujo portador deve firmar uma confissão de dívida. Esta, entretanto, é cautela suplementar, porque a operação se fez, como a outra, no mundo eletrônico. 
No caso de recurso à cartões de pagamento ou de crédito, o pagamento se faz a partir do estabelecimento de crédito, seja através da utilização de caixas eletrônicos ou terminais portáteis ou fixos situados no estabelecimento do credor.

O cartão é emitido vinculado a uma conta-corrente, isto é, ele depende da existência do crédito do portador. Assim, ele é uma versão moderna da carta de crédito rotativa. Ou modalidade eletrônica da antiga letra de câmbio, que permite à pessoa efetuar saques, totais ou parciais, contra um crédito que possui frente ao estabelecimento sacado, neste caso o emitente do cartão.

Então, o cartão poderá ser utilizado tal como acontecia com a antiga letra de câmbio - de duas formas diferentes.

Uma delas é pela sua apresentação a qualquer estabelecimento de crédito ou ao do emitente, para efetuar um saque. A palavra estabelecimento pode referir-se ao tradicional, mas, na prática, é o ATM (Automatic Teller Machine), o nosso "caixa eletrônico" pertencente a um banco ou a uma rede (como o "Caixa 24 Horas"), que presta serviços a vários bancos. Pode-se ter até mesmo a "agência eletrônica" em que várias "caixas eletrônicas" atendem à freguesia.

Nesse caso, o cartão serve para o saque, que é feito contra a contacorrente do interessado. Ele serve, também, para identificação, associado ao código ou à assinatura do portador. Como acontecia nas letras de câmbio, o sacado pode e deve ter o cuidado de exigir do portador a sua identificação, antes de pagar.

É por isso que os cartões trazem no seu verso, com a tarja magnética, a assinatura do portador, ou então, quando tem memória, para seu manuseio é preciso a introdução de um código, que faz às vezes de "assinatura eletrônica"

Todavia, numa outra forma de utilização, o estabelecimento de crédito pode não estar dispensando dinheiro diretamente ao portador do cartão. É quando recebe uma ordem de transferência de crédito de uma conta para outra, e é o que acontece na utilização de terminais portáteis.

O portador do cartão, ao efetuar uma compra, apresenta-o ao comerciante. Este cartão é introduzido num terminal portátil, ou num terminal local, e nesse aparelho o comerciante coloca os dados relativos à sua conta e ao valor da operação feita. Por sua vez, introduz também os dados do cartão do comprador. Se este for o chamado smart card, o comprador dará uma assinatura eletrônica; se ao contrário, o cartão for simples, apenas com a tarja magnética, o comprador portador apenas assinará um recibo. Este recibo assinado é um comprcvante do pagamento feito para evitar a negativa. 
$\mathrm{Na}$ verdade, no momento em que o estabelecimento comercial fez o lançamento no caixa eletrônico, a operação já se concretizou. Já passou o tempo em que, ao fim de cada semana ou cada mês, conforme o sistema adotado, os comerciantes e prestadores de serviços deviam dirigir-se ao emitente dos cartões de crédito ou pagamento para pedir o crédito das transações feitas, apresentando os respectivos boletos. Isto agora se faz automaticamente ou, como se diz, on line, momento a momento.

Aí, o cartão de pagamento ou de crédito perde a sua natureza de letra de câmbio ou de carta de crédito, para se tornar instrumento de pagamento, documento eletrônico.

\section{O que é o documento eletrônico?}

O documento eletrônico é o correspondente a uma ordem de pagamento ou transferência, emitida sobre papel. Ele é o documento que determina ao banco que faça a transferência de um valor, de uma conta para outra.

Pode ser emitido pelo banco a pedido do cliente, formulado no balcão deste banco. Tem início, neste caso, em geral, através de um documento escrito. É a fórmula mais antiga, e primitiva, porque exige a ida do cliente (ou seu preposto) até o banco. É prática que tende a desaparecer.

No caso do comércio eletrônico ocorre por meio de telecomunicação, seja a Internet, sejam os sistemas de acesso direto fornecido pelos bancos, através de linhas telefônicas, dedicadas ou-não. Aí não se necessita o suporte de papel, pois é a mídia eletrônica que recebe e registra o ato de vontade do agente e concretiza-o.

Serve para efetuar pagamentos, singulares ou repetitivos. Aí também, a função da informática é a simplificação e o diligenciamento das operações.

A emissão da ordem pelo cliente faz, automaticamente, com que todos os trâmites para a transferência do valor, da sua conta para outra, ocorram. O computador assume as funções que, antes, eram de funcionários do banco; cumpre a tarefa que lhes caberia, para fazer a transferência dos fundos de uma conta para a outra, efetuando os lançamentos contábeis (eletrônicos) cabíveis. No caso do comércio eletrônico, será da conta do comprador para a do vendedor. Fá-lo-á através da rede, (com os riscos da comunicação à distância, que vão ser discutidos mais adiante) ou agirá através de um terminal com o programa específico que o banco lhe fornece. 
Esta fórmula faz com que o crédito e o débito sejam, do ponto de vista do tempo subjetivo do operador, instantâneos e simultâneos. Entretanto, do ponto de vista do tempo real, que é o da máquina, a operação não é instantânea, pois há uma sucessão temporal de eventos, mediando apenas alguns nano segundos entre um e outro. Mas é fração de tempo imperceptível para as pessoas.

Nesses casos, há problemas jurídicos envolvidos, que espelham os encontrados nas compras e vendas feitas antes do advento dos meios eletrônicos.

O problema da lei aplicável às operações, tanto do ponto de vista temporal quanto do ponto de vista espacial, o problema das responsabilidades pelo processamento do documento, pelas emissões e pelos erros. Todos eles encontraram no passado uma resposta no Direito.

Estas operações, e isto é importante recordar, incluem as transferências eletrônicas de fundos. Estas ocorrem entre bancos e entre contas.

A moeda é escritural, mais ainda, é escritural eletrônica. Por isso, é preciso o uso dos meios eletrônicos para que exista. As transferências se fazem quer para uso bancário, isto é, na compensação de contas que fazem os bancos entre si ou nos acertos que fazem uns com os outros em relação às operações que tenham praticado, operações de câmbio, operações de redesconto recíproco, etc.

Muitas das transferências de fundo, entretanto, são feitas para atender ordens da clientela, e por sua conta. De um momento para outro os valores vão de um banco para outro, de uma conta particular para outra. Aí se ultrapassa a compensação para se chegar à transferência efetiva. Entretanto, o procedimento é similar ao da compensação.

Estas transferências são entre contas do mesmo titular ou contas de diferentes titulares. Entre as contas do mesmo titular, do ponto de vista jurídico, não apresentam grandes preocupações.

Afinal, a divisão entre diferentes contas, sob a mesma titularidade, é desinteressante do ponto de vista do direito e patrimonial, pois tudo fica dentro da mesma esfera de propriedade.

É quando os titulares são diferentes que as operações passam a ter maiores consequêencias jurídicas. Está-se, aí, na presença de dois universos patrimoniais, cada um deles afetado a uma pessoa diferente.

Nesse caso, temos de nos preocupar com a responsabilidade do janqueiro que se subdivide e espraia. $O$ erro pode ter conseqüências de maior gravidade que no outro caso. Por seu lado, esse tipo de transferência, implicando em 
variações de ordem patrimonial, deve ter uma justificativa lícita no mundo do Direito.

Como se viu, todas essas operações têm características próprias e que não-chamam a nossa atenção sob o ângulo do Direito, mas que são instigantes sob o aspecto de novidade técnica e operacional.

Haverá critérios que permitem distinguir as operações do comércio eletrônico das tradicionais?

\section{Critérios Distintivos}

A presença do elemento eletrônico é a novidade do ponto de vista da estrutura jurídica e econômica, em todas essas operações, que já existiam antes.

O que é novo, nelas, é o uso dos meios de comunicação à distância, e o fato de que estes são eletrônicos, não a sua finalidade ou estrutura.

Inova-se no sentido de que o suporte material dos instrumentos deixou de ser o papel, para ser um meio magnético, optomagnético, ótico, digital.

Aí, acontece o que apontamos no início deste texto: o retorno a uma situação semelhante a da oralidade, e a necessidade de repousar sobre memórias tãofalhas quanto as humanas.

\section{A. Presença do elemento eletrônico}

Esta é a novidade em todas essas operações que, não fora isso, seriam tradicionais, do ponto de vista do Direito.

Entretanto, algumas modificações em relação ao modus operandi também são novidades.

Elas consistem, principalmente, no fato de que muitas tarefas, que antes dependiam de seres humanos para sua execução, agora passam a ser feitas pelos próprios aparelhos. Pode-se dizer que nelas a presença humana foi descartada. É bem verdade, entretanto, que a ação das máquinas é desencadeada pela atividade de alguém que as programou ou que as aciona.

Daí podem decorrer, como decorrem, conseqüências importantes, imprevisíveis. Todos se recordam que um dos "crashes" ocorridos na Bolsa de Nova York, a célebre "terça-feira negra" foi devido, em parte, à execução automática pelos computadores das grandes sociedades corretoras de vendas sucessivas de 
títulos a preços cada vez mais baixos, derrubando as cotações. Com efeito, as máquinas estavam programadas para efetuar vendas, quando a cotação das ações baixasse um certo percentual ou superasse um certo volume. No momento em que uma delas começou a vender mais baixo, as outras máquinas, programadas da mesma maneira, passaram a vender do mesmo modo. $\mathrm{O}$ efeito cumulativo de uma venda sobre as outras, atirou os preços da Bolsa para baixo, antes que os operadores pudessem descobrir o que estava acontecendo e intervir (é bem possível que isto não venha a se repetir, porque a falha detectada seria logo sanada). Do ponto de vista do Direito cabe notar que essas operações nem por terem sido realizadas automaticamente eram inválidas, e apesar de serem virtuais os prejuízos, decorrentes das vendas eletrônicas, foram muito reais economicamente.

A presença física das pessoas foi desnecessária para que essas operações, bem ou malsucedidas, tivessem ocorrido, e os proprietários das ações perdessem dinheiro.

Isto nos leva à preocupações na ordem jurídica.

Uma delas é a de especular se operações de compra e venda desse tipo, poderiam ou-não ser consideradas como contratos válidos, já que aí não houve manifestação da vontade.

Entretanto, pode se argumentar, e o argumento parece sólido, que a vontade foi manifestada de modo genérico, universal, da mesma forma que estaria sendo a de alguém que anunciasse que compraria todos os animais soltos que aparecessem em determinada cidade. Não é necessário que para cada animal apresentado ao comprador haja uma oferta, para que ocorra o contrato. A oferta genérica vale para todos.

Outro argumento é o de que a manifestação de vontade ocorreu quando a máquina foi programada para produzir determinado resultado, e posta em marcha. Seria o mesmo que usar um gravador para ficar repetindo ofertas de produtos a pessoas que passassem diante de uma vitrine. A gravação seria o instrumento para a expressão da vontade, como o é a programação da máquina.

$\mathrm{O}$ argumento contrário é de que a programação se faz numa linguagem que o utilizador do programa em geral desconhece - a chamada linguagem de máquina e não poderia, assim, vir a exprimir sua vontade. Mas, basta refletir que, como ele conhece as conseqüências do programa, isto é, o resultado que dele se espera, isso bastaria para servir como meio para manifestar a sua vontade. 
Como se vê, o esquema tradicional de oferta e aceitação, com tudo o que implica juridicamente, continua a existir. As similitudes com as operações tradicionais, entretanto, não-afastam a inovação no modus operandi.

Aí é que as diferenças com as operações tradicionais vão aparecer

B. Diferenças entre as operações comerciais tradicionais e as eletrônicas

Elas se destacam em dois aspectos.

Um, o recurso a novos meios de comunicação e expressão, que dispensam a necessidade do papel como suporte físico para os atos praticados, e outro, quanto à desnecessidade da presença das pessoas em atos que são automatizados.

A automaticidade implica não-só na desnecessidade da presença física das partes, como também na do suporte documental da tradição, o papel.

O recurso a novos meios e a ausência de intervenção humana em muitos atos são as diferenças significativas entre as operações tradicionais e as eletrônicas que merecem ser vistas mais de perto.

\section{Elementos novos}

Como se disse, a ausência de suporte físico é o primeiro dos elementos inovadores do comércio eletrônico. Paradoxalmente, reconduz-nos à fase mais primitiva do Direito, quando a palavra escrita não-existia, e predominava a oralidade.

\section{Ausência de suporte físico}

As mudanças implicaram na adoção de uma regime jurídico especial no que concerne à prova e ao modo de exprimir e confirmar a vontade das partes. Opera-se verdadeira volta a uma oralidade, somente o meio deixa de ser o ar para ser o eletrônico. 
Aspecto formal, exteriorização, suporte

O próprio nome, comércio eletrônico, está a indicar que as operações se desenrolam nesse meio, onde o suporte mais permanente das informações é magnético (disquetes, discos rígidos, fitas, etc.), ou discos optomagnéticos ou óticos (os CDs). A memória dos computadores é volátil, e não-serve para arquivar funciona como um quadro negro para cálculos e gráficos que são apagados para um novo uso.

$\mathrm{Na}$ regulação jurídica deste aspecto dos negócios feitos por computador, o foco é na chamada desmaterialização do negócio. Isto é, o instrumento a que nos habituamos, o papel, não é mais utilizado.

$\mathrm{Se}$, como dizia Mc Luhan, "o meio é a mensagem" é no meio eletrônico que a mensagem circula. Circula e é arquivada numa linguagem que não é a nossa, mas a da máquina, ilegível para as pessoas comuns, dificilmente compreendida pelos especialistas. Para ser compreendida e manuseada recorre-se a "traduções" as chamadas "linguagens de alto nível"

Para complicar mais as coisas, há vários tipos de "chips", em torno dos quais se constróem os computadores, e cada um tem uma série de instruções que exigem um sistema operacional e um dialeto ou linguagem próprios, deles ou de sua família (Intel, RISC, etc.).

O fato de se usar um meio novo, cuja fiabilidade ainda não se avaliou plenamente, faz com que a resistência às mudanças se associe à ignorância para provocar rejeição.

Ela levou ao questionamento da validade dos registros eletrônicos como prova do negócio (associada às dúvidas quanto à existência e validade da assinatura, e a segurança das operações).

De certa forma, como disse, retornamos à oralidade do negócio. Entretanto, essa não se coadunava com a complexidade crescente dos negócios. Por isso, desenvolveu-se, progressivamente, uma estrutura formalista que respondia e responde às necessidades jurídicas de facilitar a prova da existência e o teor do negócio.

Este formalismo, que foi tão-útil por séculos, se choca, agora, com a desmaterialização típica do negócio eletrônico.

As respostas a esta situação são várias, e vão daquelas menos inspiradas, que consistem no envio posterior do papel, confirmando a realidade do 
negócio já feito, até a criação dos chamados "cartórios eletrônicơs" empresas que assumem a tarefa de certificar a existência de contratos, a autenticidade de assinaturas, ou a comprovação da emissão de ordens de pagamento.

\section{A segurança do negócio}

A primeira e principal preocupação apresentada por vendedores e compradores está na segurança do negócio. Todo o comprador quer ter certeza que, pelo preço que pagou, receberá a mercadoria que escolheu. Ela também é necessária no comércio eletrônico.

A segurança do comércio eletrônico deve ser encarada sob o foco de quatro tipos diferentes de negócios. Dois são novos: os pagamentos feitos com os cartões de crédito e transferências eletrônicas de dinheiro, e os negócios relacionados à infra-estrutura do comércio eletrônico.

Já o terceiro e quarto enfoque dos negócios feitos entre empresas e dos realizados entre uma empresa e um consumidor apenas colocou em evidência alguns aspectos, existentes também nas operações anteriores ao advento da informática.

Em todas essas modalidades a segurança depende de dois fatores.

Primeiro, a comprovação da identidade das partes onde, embora o problema esteja muito mais ligado à tecnologia do que ao Direito, este tem o seu dizer.

Começa pelo fato de que, pela teoria da aparência, e por meio de contratos, é possível estabelecerem-se nexos causais e responsabilidades nas operações eletrônicas.

Existe também o problema da fraude. Esta pode decorrer da ação de um comerciante inescrupuloso, de um operador desonesto ou de um imprevidente que facilite a terceiros a prática de crimes relacionados com a segurança da rede, seja o roubo de assinaturas eletrônicas, ou o seu uso indevido nos negócios. Isto para não falarmos, também, dos problemas causados pela má-fé de algum pretenso consumidor, usando identidade e senhas alheias.

Outro problema é o da divisão das responsabilidades. Com efeito, na cadeia que se forma do produtor até o comprador final, intervêm vários personagens, a que já nos referimos: o negociante que fez a oferta através da rede; aquele que deu abrigo ao seu estabelecimento eletrônico, o conhecido "provedor"; e também as entidades que asseguram o transporte dos dados de um para outro lado, assim como 
o "provedor de acesso" do consumidor. Intervirá, ainda, sem sombra de dúvida, o banco ou instituição financeira que efetuará o pagamento. Este também relacionarse-á com aqueles que fornecem as linhas ou instrumentos pelos quais se transfere a informação, e o provedor ou provedores do comerciante e do consumidor, envolvidos no negócio.

Para cada uma dessas partes que intervém, direta ou indiretamente, no negócio eletrônico há uma problemática jurídica.

Do ponto de vista dos provedores, a responsabilidade decorre do seu dever de zelar para que o site daquele que se vale dos seus serviços não seja invadido pelos criminosos eletrônicos ou mesmo por curiosos. Deve proteger não-só a confidencialidade dos negócios como sua segurança, sob pena de o comerciante se ver saqueado, ou os consumidores defraudados.

Terá também o dever de assegurar, além da integridade e da confidencialidade do site, a qualidade dos serviços utilizados, a velocidade, a correção e a integridade dos dados, e a conservação dos mesmos por um longo tempo.

Responderá, também, perante as autoridades do país em que se situa, pelas restrições de ordem pública a que tiver que fazer face.

Do ponto de vista do transportador de dados, isto é, aquele que fornece os meios pelos quais os dados circulam, ou que se encarrega de fazer tramitar os dados de um computador para outro (companhias telefônicas, operadoras de cabos, cogita-se mesmo nas companhias produtoras de eletricidade, cuja fiação poderia ser utilizada, usando-se critérios mais modernos, ou redes de satélites de telecomunicação), esse assume o dever de proteção e sigilo dos dados, enquanto transitem sob sua responsabilidade, assim como o da garantia da integridade e da velocidade de transmissão. São responsáveis pelos acidentes e incidentes que ocorrerem nesse trajeto. Entretanto, muitas vezes a sua atuação se fará de fora das fronteiras do país em que se situam ou o comprador ou o vendedor, ou ambos.

Então, os fornecedores de serviços estão sujeitos à lei do país em que se situa a sua sede ou em que estão os dispositivos que utilizam para a transmissão de dados, mas terão também de se sujeitar às restrições de ordem pública do país para qual os dados são destinados.

Com efeito, não seria admissível em certos países, por exemplo nos países muçulmanos, a transmissão de dados que venham a violar os preceitos da 
religião ali dominante. Há proibições severas, incidentes sobre imagens e fatos que podem ser exibidos.

Os riscos também podem decorrer de restrições que são colocadas pelo seu próprio país de origem. Por exemplo, um provedor norte-americano, por cujos computadores transitasse uma mensagem de uma pessoa qualquer eventualmente até mesmo situada fora dos EUA, e que transmitisse para um terceiro -, também não-residente, domiciliado, nem presente nesse país - informação que tivesse implicações para a segurança nacional daquele país, poderia ser objeto de sanções. O exemplo mais clássico refere-se aos algoritmos de criptografia.

\section{Internacionalidade das operações, implicações jurídicas}

A internacionalidade presente em quase todas as transações eletrônicas acrescentará mais uma complicação no campo do Direito.

Realmente, as regras tradicionais do conflito de leis não teriam como ser aplicadas, de modo prático e eficaz, nas novas situações que aparecem:

Aonde se situa a operação eletrônica?

No computador que faz a pergunta ou naquele que dá a resposta?

No que registra o teor do contrato ou no que o arquiva?

Todas estas são questões a discutir e que infelizmente os limites de tempo nos impedirão de examinar.

São Paulo, janeiro de 1999. 